\title{
THE EURO IN THE INTERNATIONAL FINANCIAL ARCHITECTURE
}

\author{
J. BRAGA DE MACEDO ${ }^{1}$ \\ (Received: 5 March 2001; revision received: 10 May 2001; \\ accepted: 29 May 2001)
}

\begin{abstract}
The procedures governing exchange rate policy among EU members in the early 1990s, whilst largely unwritten, provided convergence and cohesion across the region. Suitably adapted, this ERM code of conduct might help developing, emerging and transition countries face the challenge of globalisation. The perspective on international financial architecture proposed in this paper assumes that the same forms of peer pressure that brought about the euro will also sustain the required institutional change outside Europe. Nevertheless, the euro is an enabling reform that calls for additional structural adjustment. Structural reforms are needed to enhance the potential of the euro as a world currency and also the competitiveness of European firms. The European common good notwithstanding, institutions of global economic and financial governance, helped afflicted countries recover from financial crises in 1997-1999. Regional and global mechanisms for multilateral surveillance must be complements, not substitutes.
\end{abstract}

Keywords: European Monetary System, code of conduct, international financial architecture, Euro System and Exchange Rate Regimes

JEL classification index: F3, O1

1 Earlier versions were presented at the 6th EACES Conference in Barcelona, 8 September 2000 and at DELTA, Paris during the 24 November Journée Jourdan. I am grateful to participants, especially Mario Nuti, Daniel Cohen and Helmut Reisen for comments and to Thomas Chalaux for research assistance. Additional insights came from the discussion at the CEPR Executive Committee meeting of 31 January 2001. The views expressed remain personal and do not involve the OECD Development Centre.

Correspondence: J. Braga de Macedo, President, OECD Development Centre, 94 rue ChardonLagache, 75016 Paris, France. E-mail: jbmacedo@oecd.org 


\section{INTRODUCTION}

Co-ordination mechanisms among monetary and fiscal authorities like the ones found in the European Union (EU) have been the best response to threats of contagion of national crises. In effect, the current international system goes beyond American national interest in preserving world stability and it calls for more effective regional and global responses adapting EU methods. In Macedo (2000b), this adaptation is called "Eurocentric". The term is explained and examples are provided from the Central European Free Trade Association (CEFTA), the Association of South East Asian Nations (ASEAN) and the Southern Common Market (Mercosur). The evolution of the swap arrangements between ASEAN, China, Japan and Korea (the so-called Chiang Mai initiative) towards more systematic macroeconomic consultations and the creation of a "macroeconomic monitoring group" in Mercosur go in the same direction.

The crises in the Exchange Rate Mechanism (ERM) of the European Monetary System (EMS) were overcome by more effective co-ordination mechanisms among monetary and fiscal authorities which led to the creation of the euro. Section 2 looks at the experience of the EMS, and shows how the response to the 1992-93 crises reinforced the ERM code of conduct and therefore the foundations of the eurosystem.

Section 3 looks at European and international financial architecture. Section 4 draws lessons for emerging markets, contrasting regional and global mechanisms for multilateral surveillance. Regional co-ordination mechanisms among monetary and fiscal authorities are consistent with global plans for the reform of the international monetary system, as long as the institutions of global governance are capable of preventing reversions into trade or financial protectionism. Section 5 concludes on the complementarity between the euro and global financial architecture.

\section{THE EXPERIENCE OF THE EMS}

\subsection{The evolution of the ERM}

After the demise of the Bretton Woods system of fixed but adjustable exchange rates in 1973, various continental arrangements to stabilise exchange rates were tried, the last of which was the European Monetary System (EMS), created in 1978 by a Resolution of the Council of Finance Ministers of the Union (EcoFin) and supported by an agreement among participating central banks. 
The primary objective of the 1986 Single European Act was achieving free trade in goods, services and assets, as well as free movements of people among twelve nation states. In turn the abolition of internal borders created market pressure for stable exchange rates in terms of the European Currency Union (ECU) basket.

Most member states changed their economic regime towards fiscal discipline and stable prices after realizing that they could no longer improve export competitiveness by engineering exchange rate devaluations. This followed the creation of the ERM, with the Netherlands foregoing devaluation after 1982 and France after 1983. Poorer states took longer to be convinced but - as discussed next - the economic regime did change in Ireland after 1987, in Spain after 1989 and in Portugal after 1992.

The EMS functioned without any realignment after January 1987 and the progress towards the single currency accelerated. At the Madrid European Council in 1989, the report of a Committee of Central Bank Governors chaired by the President of the European Commission (EC) was accepted as a basis for Economic and Monetary Union (EMU). The single currency was to be achieved in three stages, beginning 1 July 1990. Rather than relying on national reserve currencies, a new currency was chosen, the ECU (it was renamed euro at the Madrid European Council of 1995).

Over the years, a code of conduct has been built up as the ERM developed from a mere exchange rate arrangement into a powerful convergence instrument. In addition to compulsory intervention, for unlimited amounts, at the agreed bilateral limits and to the need to reach a consensus for modifying a parity; the Basle-Nyborg Agreement called for convergence to establish and maintain stable exchange rates. The rules also refer to the creation of ECU's through swap operations, to the provision of currencies for intervention purposes, to the settlement of claims arisen from intervention, and so on.

The ERM code of conduct implied the acceptance of the German mark as the anchor of the system and thus the recognition of the leadership of the Bundesbank. It gave a prominent role to co-ordinated interest rate changes in the management of the system and also involved a consensus on crisis management.

Shortly after the first stage of EMU began, the United Kingdom joined the ERM. Sterling appeared to trade its past allegiance to the broad Atlantic standard for a narrower continental bloc. This first experience lasted less than two years but it involved the United Kingdom in the design of a multilateral surveillance framework (MSF), which turned out to be decisive for the sustainability of the system.

With respect to the MSF, the rules of the game changed for all the member states. Without such a broad base, the MSF would have been less credible and might consequently have hindered the governance of the eurosystem. This em- 
phasis on the MSF also reflects the finding, going back to Cooper (1968), that the costs and benefits of co-operative responses to growing interdependence depend on the co-ordination of domestic institutions.

\subsection{The need for a regime change}

The plans for the single currency were agreed upon at the Maastricht European Council in late 1991. They were conditional upon convergence and cohesion, as explained in section 3.1 below. The second stage of EMU was set to begin on 1 January 1994. The third and final stage of EMU was to begin after the 1996 revision of the Treaty signed at Maastricht if convergence was sufficiently high, and in 1999 if not.

A medium term orientation of macroeconomic policy, coupled with measures designed to improve the functioning of factor markets and of the public sector, is favoured in principle. In transition and developing economies, though, the institutional framework for such an orientation is lacking, so that the rules for monetary stability are not credible. The expectation of EU membership, under conditions of convergence and cohesion, provides this credibility. In contrast with the Asian and Latin American experiences mentioned at the outset, candidates for membership have not been willing to set up a MSF among themselves. Even when an institutional vehicle like CEFTA is potentially available, the strict definition of trade policy has prevented any systematic discussion of related issues like finance or agriculture.

Yet it is through setting up a credible MSF that geographical peripheries can acquire global reputation. In a sense, they overcome the cost of physical distance through financial proximity. Of course initial and terminal conditions matter as much as the capacity to transform. Doctrinal controversies often reflect different assumptions about each one of these three factors. The principle of a stability-oriented policy based on the respect of property rights and open markets goes back to the gold standard, and reflects "rules of good housekeeping" valid at the core and at the periphery (Bordo and Rockoff, 1995; Macedo, Eichengreen and Reis, 1996).

For EMU, "sustained regime change" was identified in EC (1990, chapter 9) as a condition for benefits to accrue to peripheral nations or regions. This argument was especially strong under the limited labour mobility and flexibility, coupled with low fiscal redistribution among states, which prevails in the European economy. In these circumstances, exchange rate adjustments may become necessary to eliminate declines in competitiveness, but they may not succeed in changing rela- 
tive prices. The greater the underlying capital mobility and the more likely the repetition of exchange rate adjustments are, the less effective devaluation will be.

EC (1990) also used survey data to suggest that firms did not expect devaluation to solve their problems, but rather thought that credit constraints were a more severe hindrance to expansion at the peripheries than at the centre. The fear that restrictions on fiscal policy called for by the excessive deficit procedure (EDP) contained in the Maastricht Treaty - and later reinforced by the Stability and Growth Pact (SGP) - would hurt growth and prosperity was addressed in Buti et al (1997). They showed that the retroactive application of the SGP would not have exacerbated recessions over the 1961-97 period.

Yet enhancing price and exchange rate stability and buttressing the soundness of public finances is a formidable task in countries with histories of high inflation, where neither the social partners nor public employees automatically appreciate the benefits of the regime change that the policymakers are attempting to engineer.

Errors in policy appraisal can unduly raise the costs of reform, when information about the change in regime is not readily available to international financial markets. Repeated market tests of the authorities' commitment to exchange rate stability may result from this imperfect information. If these tests of the authorities' resolve greatly increase the cost of defending the exchange rate, they can lead to policy reversals. Conversely, if the volatility of the exchange rate is a direct consequence of system turbulence, market tests will be short-lived and the threat of a reversal will become less and less credible, both abroad and at home.

Since its meeting in Brussels in late 1993, the European Council has been issuing "broad guidelines" against which policy and performance in the member states are to be gauged, which has become a regular test of the MSF for all EU member states. The progress of policy reform stands on how effective this MSF might be among union officials whose interaction with national officials should be accountable in their respective parliaments and in the European Parliament.

The time it takes for a nation to acquire a reputation for financial probity varies, but it typically involves several general elections where alternative views of society may confront each other. The number of years most frequently cited in financial circles is 10 . This suggests that it may be better to take time and set on foot a self-reinforcing process of reform than to attempt a succession of overly ambitious and excessively drastic measures that will ultimately fail, damaging policy credibility.

To construct a social consensus domestically, credible signals that the authorities are committed to reform may be needed. If stable democratic governments succeed in implementing reforms, which help to achieve convergence between 
poorer and richer nations and regions, they can set off a self-reinforcing virtuous cycle of stability and growth. On the other hand, there will be a vicious cycle if short-lived governments, fearing the social conflicts associated with reforms, delay implementation and impair convergence. The cases of Spain, Greece and Portugal discussed in Bliss and Macedo (1990) confirm both the need for the regime change and the difficulty in bringing it about without overcoming the resistance of vested interests.

The initial conditions a government inherits may limit the alternatives at its command. For example, the 1992-93 recession aggravated the plight of Europe's unemployed, making it more difficult to reduce the generosity of unemployment benefits. At the same time, by demonstrating the costs of labour market rigidities and the importance of competitiveness at the firm level, the experience of the 1992-93 recession may have actually encouraged structural adjustment and, ultimately, cohesion.

\subsection{Managing the ERM crises}

In the spring of 1992, all Community currencies except the Greek drachma were in the ECU parity grid. But the Atlantic dimension was very weak. Even in the presence of sterling, the continental bloc continued based on the German mark. Indeed, it included currencies of countries in the European Free Trade Association, which were to become members of the Union, like Finland and Sweden. In September 1992, sterling and the Italian lira left the ERM. Until August 1993, political instability and speculative attacks on the grid interacted with a severe recession and the highest unemployment the Community ever witnessed.

The currency crises threatened the reputation for financial stability in small national markets, to the extent that national policies became less relevant than the proximity to a turbulent large market. Examples of this effect of "geographic" rather than "economic" fundamentals on the value of currencies were provided by Portugal and Ireland, who suffered currency attacks based on what was happening to the Spanish and British currencies. The attacks were short-lived but they nevertheless led Ireland to request a realignment in January 1993, and Portugal had partly to follow several realignments of the peseta.

Using a technique of analysing changes in the variance of the exchange rate, which was first applied to the US stock market, Macedo, Nunes and Covas (1999, MNC hereafter) report probabilities of the volatility of the weekly exchange rate between the German mark and the Portuguese escudo. The sample period goes from 7 January 1987 until 15 October 1998 (614 observations). MNC present specifications with two, three, four and five volatility states and argue that the best 
specification has five volatility states. In Tables 1 and 2 , the results from the best specification were updated until 30 December 1998. In the last weeks before the creation of the euro, a rise from the "very low" to the "low" volatility state is observed. Yet during the period proceeding the widening of the bands in August of 1993 the results remained essentially the same. When the difference between the results in $\mathrm{MNC}$ and the ones in Tables 1 and 2 is greater than or equal to $5 \%$, this is reported after the date.

The period begins in April 1992 with the last accession to the ERM before the crisis. This includes some of the realignments involving the peseta and the escudo. In Table 1, the shift from "high" to "very high" volatility shows the incidence of a currency crisis. The few instances of "very low" volatility in the sample show instead massive intervention by the Central Bank shortly before the November 1992 realignment. In Table 2, there is no instance of this "artificial stability", suggesting that the code of conduct had meanwhile been learned by the Bank of Portugal. Given that the financial reputation of the country was not fully established as the regime change was quite recent, this serves as an illustration of the power of the ERM code of conduct as a convergence instrument. The case of Portugal is one where the regime change was gradual because of the need to combine selling political stability at home and earning credibility abroad (Macedo, 1996).

A related reason is that testing the ERM parity made sense when the real appreciation was perceived as excessive by export-oriented firms and the government may have been sensitive to their pressure.

The reason why the convergence process was not hurt by the decision to widen the band was that external credibility, while necessary for medium-term policy credibility of any nation-state, is never sufficient. This was again apparent in the turbulence in early March 1995, which led Spain to ask for a new realignment in spite of fairly sound fundamentals. The lack of political stability was undermining the confidence in the currency.

As it turns out, after this realignment, Italy joined the ERM in late 1996 and Greece followed in early 1998, consolidating their own regime changes. At one time or another, all of the EU member states followed the ERM code of conduct. Austria joined with accession in 1995 and Finland in October 1996. Sweden shadowed the ERM before the 1991 banking crisis.

The single market for financial services, established in 1993, also built on the operation of the ERM code of conduct. In effect, the gradual acceptance of stability-oriented policies is at the heart of such a code of conduct. This is why it remained valid after the widening of the bands, even though the obligation of compulsory intervention for unlimited amounts at the agreed bilateral limits was unlikely to be applied. 
Table 1

Chronology of the ERM crises regime (from the entry to the first realignment)

\begin{tabular}{|c|c|c|c|c|}
\hline \multirow{2}{*}{ Date } & \multicolumn{4}{|c|}{ Smoothed probabilities } \\
\hline & Very low & Medium & High & Very high \\
\hline 04/08/92 (10+) & $0 \%$ & $4 \%$ & $72 \%$ & $24 \%$ \\
\hline 04/15/92 (10+) & $0 \%$ & $3 \%$ & $71 \%$ & $27 \%$ \\
\hline 04/22/92 (8) & $0 \%$ & $0 \%$ & $63 \%$ & $37 \%$ \\
\hline 04/29/92 (7) & $0 \%$ & $0 \%$ & $64 \%$ & $36 \%$ \\
\hline $05 / 06 / 92$ & $0 \%$ & $0 \%$ & $78 \%$ & $22 \%$ \\
\hline 05/13/92 & $0 \%$ & $0 \%$ & $85 \%$ & $15 \%$ \\
\hline $05 / 20 / 92$ & $0 \%$ & $1 \%$ & $91 \%$ & $8 \%$ \\
\hline $05 / 27 / 92$ & $0 \%$ & $1 \%$ & $93 \%$ & $6 \%$ \\
\hline 06/03/92 & $0 \%$ & $2 \%$ & $93 \%$ & $5 \%$ \\
\hline $06 / 11 / 92$ & $0 \%$ & $1 \%$ & $91 \%$ & $7 \%$ \\
\hline 06/17/92 & $0 \%$ & $1 \%$ & $87 \%$ & $11 \%$ \\
\hline $06 / 24 / 92$ & $0 \%$ & $1 \%$ & $81 \%$ & $17 \%$ \\
\hline 07/01/92 & $0 \%$ & $0 \%$ & $65 \%$ & $35 \%$ \\
\hline 07/08/92 & $0 \%$ & $0 \%$ & $48 \%$ & $52 \%$ \\
\hline 07/15/92 & $0 \%$ & $0 \%$ & $30 \%$ & $70 \%$ \\
\hline $07 / 22 / 92$ & $0 \%$ & $0 \%$ & $34 \%$ & $66 \%$ \\
\hline 07/29/92 & $0 \%$ & $0 \%$ & $30 \%$ & $70 \%$ \\
\hline 08/05/92 & $0 \%$ & $0 \%$ & $26 \%$ & $74 \%$ \\
\hline $08 / 12 / 92$ & $0 \%$ & $0 \%$ & $21 \%$ & $79 \%$ \\
\hline 08/19/92 & $0 \%$ & $0 \%$ & $6 \%$ & $94 \%$ \\
\hline $08 / 26 / 92$ & $0 \%$ & $0 \%$ & $21 \%$ & $79 \%$ \\
\hline 09/02/92 & $0 \%$ & $0 \%$ & $27 \%$ & $73 \%$ \\
\hline 09/09/92 & $0 \%$ & $0 \%$ & $26 \%$ & $74 \%$ \\
\hline 09/16/92 & $0 \%$ & $0 \%$ & $16 \%$ & $84 \%$ \\
\hline $09 / 23 / 92$ & $0 \%$ & $0 \%$ & $13 \%$ & $86 \%$ \\
\hline 09/30/92 & $0 \%$ & $0 \%$ & $5 \%$ & $95 \%$ \\
\hline $10 / 07 / 92$ & $87 \%$ & $0 \%$ & $6 \%$ & $6 \%$ \\
\hline $10 / 14 / 92$ & $93 \%$ & $0 \%$ & $6 \%$ & $1 \%$ \\
\hline $10 / 21 / 92$ & $93 \%$ & $0 \%$ & $7 \%$ & $0 \%$ \\
\hline $10 / 28 / 92$ & $92 \%$ & $0 \%$ & $8 \%$ & $0 \%$ \\
\hline $11 / 04 / 92$ & $83 \%$ & $0 \%$ & $16 \%$ & $0 \%$ \\
\hline $11 / 11 / 92$ & $0 \%$ & $0 \%$ & $99 \%$ & $0 \%$ \\
\hline $11 / 18 / 92$ & $0 \%$ & $0 \%$ & $98 \%$ & $1 \%$ \\
\hline $11 / 25 / 92$ & $0 \%$ & $0 \%$ & $96 \%$ & $4 \%$ \\
\hline
\end{tabular}

Source: MNC updated until end 1998.

(Numbers in parentheses after date refer to difference with MNC when larger than or equal to $5 \%$.) 
Table 2

Chronogy of the ERM crises regime

(from the first realignment to the widening of the bands)

\begin{tabular}{|c|c|c|c|}
\hline \multirow{2}{*}{ Date } & \multicolumn{3}{|c|}{ Smoothed probabilities } \\
\hline & Medium & High & Very high \\
\hline $12 / 02 / 92$ & $0 \%$ & $96 \%$ & $4 \%$ \\
\hline $12 / 09 / 92$ & $0 \%$ & $93 \%$ & $7 \%$ \\
\hline $12 / 16 / 92$ & $0 \%$ & $90 \%$ & $10 \%$ \\
\hline $12 / 23 / 92$ & $0 \%$ & $84 \%$ & $16 \%$ \\
\hline $12 / 30 / 92$ & $0 \%$ & $88 \%$ & $12 \%$ \\
\hline $01 / 06 / 93$ & $0 \%$ & $87 \%$ & $13 \%$ \\
\hline $01 / 13 / 93$ & $0 \%$ & $92 \%$ & $8 \%$ \\
\hline $01 / 20 / 93$ & $0 \%$ & $93 \%$ & $7 \%$ \\
\hline $01 / 27 / 93$ & $0 \%$ & $95 \%$ & $5 \%$ \\
\hline $02 / 03 / 93$ & $1 \%$ & $95 \%$ & $4 \%$ \\
\hline $02 / 10 / 93$ & $1 \%$ & $94 \%$ & $6 \%$ \\
\hline $02 / 17 / 93$ & $0 \%$ & $89 \%$ & $11 \%$ \\
\hline $02 / 24 / 93$ & $0 \%$ & $92 \%$ & $8 \%$ \\
\hline 03/03/93 & $0 \%$ & $93 \%$ & $6 \%$ \\
\hline 03/10/93 & $1 \%$ & $94 \%$ & $5 \%$ \\
\hline 03/17/93 & $3 \%$ & $95 \%$ & $3 \%$ \\
\hline $03 / 24 / 93$ & $3 \%$ & $94 \%$ & $2 \%$ \\
\hline $03 / 31 / 93$ & $5 \%$ & $93 \%$ & $2 \%$ \\
\hline 04/07/93 (5) & $6 \%$ & $91 \%$ & $3 \%$ \\
\hline $04 / 14 / 93$ (6) & $7 \%$ & $89 \%$ & $4 \%$ \\
\hline $04 / 21 / 93$ (6) & $7 \%$ & $84 \%$ & $9 \%$ \\
\hline $04 / 28 / 93$ (6) & $7 \%$ & $75 \%$ & $18 \%$ \\
\hline $05 / 05 / 93$ (5) & $6 \%$ & $56 \%$ & $38 \%$ \\
\hline $05 / 12 / 93$ & $0 \%$ & $10 \%$ & $90 \%$ \\
\hline 05/19/93 & $0 \%$ & $0 \%$ & $100 \%$ \\
\hline $05 / 26 / 93$ & $0 \%$ & $1 \%$ & $100 \%$ \\
\hline $06 / 02 / 93$ & $0 \%$ & $0 \%$ & $100 \%$ \\
\hline 06/09/93 & $0 \%$ & $0 \%$ & $100 \%$ \\
\hline $06 / 16 / 93$ & $0 \%$ & $2 \%$ & $98 \%$ \\
\hline $06 / 23 / 93$ & $0 \%$ & $4 \%$ & $96 \%$ \\
\hline $06 / 30 / 93$ & $0 \%$ & $4 \%$ & $96 \%$ \\
\hline 07/07/93 & $0 \%$ & $4 \%$ & $96 \%$ \\
\hline $07 / 14 / 93$ & $0 \%$ & $0 \%$ & $100 \%$ \\
\hline $07 / 21 / 93$ & $0 \%$ & $0 \%$ & $100 \%$ \\
\hline $07 / 28 / 93$ & $0 \%$ & $0 \%$ & $100 \%$ \\
\hline 08/04/93 & $0 \%$ & $44 \%$ & $56 \%$ \\
\hline
\end{tabular}

Source: Same as for Table 1. 
The need to reach a consensus for modifying the central rate remained, as the parity grid was not changed by the decision to widen the fluctuation bands. It is also noteworthy that the economic priorities of the Treaty (low inflation, sound public finance, medium-term stability framework) remained undisputed among member states and Community institutions, stressing the need for convergence to establish and maintain stable exchange rates.

During the second stage of EMU, the MSF designed to ensure convergence of national economies towards price stability and sound public finances became binding. The EDP, in particular, determined whether or not a member state could adhere to the single currency. Since convergence was not achieved in a majority of national economies, the EcoFin Council approved the SGP to ensure that the entry conditions for EMU would continue to be met after the euro was created and set the beginning of the third stage for 1999 .

\subsection{The widening of the ERM fluctuation bands}

With high capital mobility, exchange rate stability requires a speedy real and nominal convergence process. The indicators of budgetary discipline have become signals of regime change sustained by the structural reform of the public sector.

Given that financial markets tend to exaggerate rather than to dampen such signals, apparent reversions during a relatively rapid convergence are also more liable to misinterpretation. The cohesion objective involves a degree of social awareness that may not be required with respect to the convergence of fiscal variables. In any event, whatever the credibility of national policies, it became apparent during the first stage of EMU that fast convergence was more difficult with slower growth. Moreover, during the transition, the main macroeconomic costs arise before the main microeconomic benefits are felt.

The Treaty convergence criterion relating to exchange rate stability requires the observance of the "normal fluctuation margins" during two years, and they not having been involved in any realignment during the same period (or at least not having initiated one). Maintaining the currencies within the parity grid is the result of more than intervention by participating central banks. It reflected the credibility of national policies especially in Germany, and also that of the entire EMS relative to the dollar or the yen.

If, in the final analysis, the exchange rate reflects the credibility of national policies over the medium term, it may do so with considerable noise if the entire parity grid is under attack. This is why little indication about the credibility of national policy could be gathered from the realignments, which occurred during this period. Speculative attacks on more vulnerable currency parities will have more 
negative effects on the system if parities are already locked than if they continue to be flexible. Flexibility within a sufficiently wide band allows speculation not to be a one-way bet. That lesson was learned in the twelve months proceeding 2 August 1993 when very wide bands of $15 \%$ replaced the normal fluctuation margins. The temporary nature of the move notwithstanding, these new "normal fluctuation margins" eliminated the need for exceptional measures, such as exchange controls, designed to deal with a protracted second stage of EMU.

As can be gathered from Table 1 above, foreign exchange market turbulence began in late August, early September 1992 when dollar interest rates fell substantially. In the meantime, German short-term interest rates remained high. Pressures for wage increases increased the reluctance of the Bundesbank in acknowledging that a European wide recession was imminent. The policy conflict led to the exit of some currencies from the ERM and to speculative attacks against others. The attack of July 1993 (pictured in Table 2 above for one bilateral rate) was so massive that an emergency meeting of the EcoFin Council including Central Bank Governors was convened and exchange rate fluctuation margins were broadened to $15 \%$ on each side of the parity.

The $15 \%$ wide band was not used by any participating central bank and margins of $2.25 \%$ were observed between the German mark and the Dutch guilder. The basic difference relative to the previously normal fluctuation margin was the absence of one-way bets on parities. The external discipline provided by the grid no longer obtained and each central bank decided whether or not to intervene within the old fluctuation bands. Most decided to do just that, so that the convergence process was not hurt by the decision to widen the band.

The lesson from the currency crises is that the largely unwritten ERM code of conduct implied more effective co-ordination mechanisms among monetary and fiscal authorities than expected. Non-compliance with the code of conduct played a major role in the development of the currency turmoil, but the system regained stability after 2 August 1993, thanks to the widening of the fluctuation bands, which limited speculative pressure by eliminating one-way bets and reintroducing two-way risks.

The option to float in order to fix, a kind of financial "cruel to be kind" (Macedo, 2001, using a line from Hamlet, which made its way into a pop song) shows that the set of principles, rules and code of conduct, which underlie the monetary union in stage two have proven correct for the euro as well.

That the widening of the bands was a positive step towards the euro may easily be accepted nowadays. That you may float in order to fix introduces the earning credibility process explicitly in what is the major lesson from the EMS experience. When the decision to widen the bands was taken, however, many observers and prominent economists stated that the EMS and the euro were dead. 
With respect to the exchange rate regime, and except for the German mark, the former national currencies of the eurosystem could neither float nor credibly fix without the MSF institutionalised in the 1992 Maastricht Treaty (including the introduction of the EDP). The pound sterling and the Swedish krona follow an inflation-targeting monetary rule, which allows the exchange rate to float, but in fact the latter has been fairly stable against the euro.

Calvo (2000) discusses the similarities between hard pegs and inflation targeting in emerging markets. The question of credibility is different in EMU members because, thanks to the ERM code of conduct, they are more used to follow a MSF. Intermediate solutions, between the pure float and the currency board, are sometimes taken to be too complex to be credible but the credibility of an exchange rate regime cannot be judged in general. Since the best indicator of policy credibility is that a MSF exists and is effective, it is the MSF that determines the choice of an exchange rate regime. This is also why the MSF in the eurosystem should not neglect trends in the current account (Decressin and Dysiatat, 2000).

\section{EUROPEAN AND INTERNATIONAL FINANCIAL ARCHITECTURE}

\subsection{Convergence and cohesion as common good}

The current international system calls for a more effective regional and global response to threats of contagion of national crises. American national interest in preserving world stability is one such response. Co-ordination mechanisms among monetary and fiscal authorities like the ones found in the EU and in the eurozone rely on economic and societal values shared among sovereign states are another response. American and European interests have been complementary on many occasions and indeed originated over fifty years ago in the process of allocating Marshall aid through the European Payments Union and the Organisation of European Economic Co-operation, which later became the OECD. The current relevance of these distant origins is described in joint work with Eichengreen (1999). Bergsten (2000) provides a list of similarities and differences between European and Asian integration, and concludes that the former are beginning to outweigh the latter.

Under globalisation, no single country can provide the "common global good". The global applicability of the European experience to the search for the "common good" hinges then on the "centre" in Europe not being a nation-state, but rather a community thereof. The adaptation of the ERM code of conduct to improve international financial architecture would thus support the creation of new networks including major emerging markets, as long as they manage to enforce fi- 
nancial stability. This applies to the Financial Stability Forum and to the G-20, for example.

Enforcing financial stability can lead to a virtuous cycle, whereby currency stability feeds back to a more employment-friendly economic environment. Conversely, when terminal conditions lack credibility, a "stop-go" convergence process that hinders change may appear. Temporary, unaccountable shifts in sentiment in financial markets thus may disrupt the convergence process permanently. A government can only protect itself from this threat by acquiring a reputation for subordinating other goals of economic policy to the pursuit of convergence.

The MSF can play a role in providing timely information on national economic policies in a way that enhances the reputations of deserving governments. The same is true of the adoption of appropriate budgetary procedures at national and union levels.

Thanks to its code of conduct, the ERM acted as an instrument of convergence towards the single currency. While largely unwritten, the code encompassed instruments specified in the Maastricht Treaty. These were essentially three stages of a timetable: the convergence programmes and the specific procedures included in the MSF, especially the ones dealing with excessive budget deficits (EDP). In addition, progress towards independence of national central banks was impressive during stage two of monetary union, as was the fact that the public sector could no longer be financed by central banks or by privileged access to financial institutions.

The European Monetary Institute was established at the end of stage one in order to contribute to the realisation of the conditions necessary for the transition to stage three. The creation of the European Central Bank (ECB) also proceeded on schedule at the end of stage two. The fact that it was delayed from 1997 until 1999 may actually have helped to prevent an excessively fast politicisation of monetary policy. The politicisation would increase the temptation to soften the excessive deficit procedure, raising fears that some governments will expect to be bailed out by the union, in contradiction to Article 104b of the 1992 Maastricht Treaty.

The approval in 1996 of the stability pact (SGP) also contributed to allay such fears because - as mentioned in section 2.2 above - it actually tightened the EDP. The creation of the ECB at the end of stage two of the monetary union proceeded on the schedule, in spite of a political dispute about the term of the initial governor.

Once again, an effective MSF, supported by all member states, was decisive for medium-term policy credibility at national and union level. Indeed, all of these instruments and procedures effectively delivered convergence and cohesion. Together with political stability or social consensus and national cohesion, the MSF delivered convergence. Social consensus implies, first and foremost, that social 
partners and public opinion understand and accept the medium-term stance of economic policy. In particular, trade unions must recognise the perverse interaction between price and wage increases, which hurts the poor and unemployed disproportionately. With the feedback of wages into prices in operation, price stability will not be durable without wage moderation. The social acceptance of these norms can be turned into a factor of national cohesion if the government takes the leadership in wage negotiations for the public-sector employees.

A single market with a single currency reflects a particular combination of private and public goods, determined by the mobility of the tax base and the availability of inter-regional or inter-national transfers. Article B of the Maastricht Treaty refers to "the strengthening of economic and social cohesion" as instruments of "economic and social progress which is balanced and sustainable". Therefore, some income redistribution among nation-states is supposed to correct the economic geography that market integration brought about. As this should not be a pretext for creating an additional burden on enterprises, the structural funds directed to member states have been made conditional on appropriate policies.

Such conditionality turned out to be difficult to agree upon at the Maastricht European Council, and accordingly cohesion countries were reluctant about the proposals for flexible integration made during the preparation for the 1996 revision of the Treaty. This reluctance has been overcome, as discussed next. But it reinforces the perception that poorer member countries are more favourable than richer ones towards political integration along sheer income redistribution lines. Such perception is not only detrimental to cohesion, it also feeds the fears of a future European "superstate" where taxation would be excessive because of international redistribution, an extremely unlikely scenario.

Where local financial monopolies exist, differences between interest rates at the core and at the periphery may endure, even in the presence of full currency convertibility and perfect capital mobility among core markets. Belonging to the convertibility and stability club is nevertheless useful to the extent it signals to market participants that the country is keen on achieving external credibility with relying not only on instruments it could control - and might therefore manipulate.

A converging country is attempting to buy domestic credibility for its efforts. This is the only way in which the national authorities could escape the adverse selection bias from which new participants in the international capital market have been shown to suffer. The instruments and procedures underlying the ERM code of conduct delivered convergence and cohesion because of the earned credibility and of the "common European good". The notion of medium-term policy credibility emerges as essential in the evaluation of the EU MSF.

Now the European System of Central Banks (ESCB) provides price stability in the eurozone by means of a single monetary policy but the institutional framework 
of the eurosystem draws on the functioning of the EMS based on a common (now single) monetary policy, and on national fiscal policies. The single monetary policy is conducted by the ESCB led by the ECB and independent of national governments and of the EC. The national fiscal policies are co-ordinated by multilateral surveillance procedures. These include the SGP; they are monitored by the Euro Group (which gathers the Ecofin Council members from the eurosystem) and by the EcoFin Council itself.

Yet the ESCB, the Euro Group and the SGP together do not quite match the "rules of good housekeeping" of the gold standard because some features of the articulation between the single monetary policy and national fiscal policies remain ambiguous. Is the ESCB accountable to the European parliament, national parliaments, both or neither? Who is responsible for exchange rate policy? No matter how crucial, these aspects are not alone responsible for the observed weakness of the euro relative to the dollar and the yen (Gros et al., 2000).

\subsection{Peer pressure and yardstick competition}

Looking at the EU as a more ambitious attempt to promote rules of good conduct among its members helps to draw lessons for other countries and regions. But it must be stressed that the Bretton Woods institutions and WTO also played a role in spreading the results of alternative policy paths among their member states. The wide acceptance observed suggests that national policymakers stabilised, liberalised and privatised the economy in part because they saw other policymakers do the same.

The issue of whether peer pressure brings about improved performance has been addressed by Besley and Case (1995) in the context of "yardstick competition", a term coming from industrial organisation, which suggests comparing similar regulated firms with each other (Shleifer, 1985). For any given firm, the regulator uses the costs of comparable firms to infer a firm's attainable cost level. Conversely, if the regulator equates the price to the marginal cost of the firm itself, then managers have no incentive to reduce cost. Using the costs of comparable firms (or their average excluding that of the firm itself, which serves like a fictitious "shadow firm") prevents the firm's choice to have an effect on the price it gets. As comparable firms may not exist or be observable, a scheme of yardstick competition may not fully overcome moral hazard problems, but it is certainly preferable to the traditional procedure of comparing current and future costs to past performance.

The peer pressure scheme is thus susceptible to manipulation by participating firms, but the difficulty in co-operating to impose collusive behaviour makes this 
perverse outcome less likely. Note also that in the case where heterogeneity is observable and can therefore be corrected for, Shleifer (1985) shows that a regulatory scheme based on peer pressure should lead to a superior performance.

This implies that the regulator can credibly threaten to make inefficient firms lose money and cost reduction can therefore be enforced. When national objectives are at stake, best practices can thus be achieved, rather than allowing a convergence towards the mean. Conversely, when peer pressure is used to stall reforms, rather than to promote them, the outcome is equivalent to the collusive equilibrium and an alternative yardstick must be devised.

Therefore, adapting the same reasoning, when there is peer pressure among national policymakers to follow best practices, these are likely to become more and more accepted. Peer reviews have enhanced competition for better macroeconomic and trade policies among OECD members. Similar benchmarking has begun with respect to structural policies, especially those relating to the regulatory framework. The greater complexity of such policies makes them more susceptible to procrastination, and the same problem has been observed in the EU, as discussed in section 3.4 below. This hinders institutional change and makes corporate and political governance more difficult.

The MSF developed among EU nation-states can be adapted to build a global financial architecture resilient to financial crises. To begin with, its intercontinental domain reflects longstanding cultural and commercial ties. Moreover, the EU probes into budgetary procedures and corporate governance standards in ways that may offend national sovereignty if applied to Washington or Tokyo. In the OECD peer reviews and in the standards agreed upon at the BIS, unanimity is required so that national sovereignty is entirely preserved. The role of the Commission as regulator and that of the Court of Justice help bring procedures closer to a regulatory framework allowing for yardstick competition.

Among the G-7, only the four European states have attempted to deal explicitly with their regional architecture, so that the presidents of the European Commission (EC), Central Bank (ECB) and Council (especially the EcoFin) attend the meetings. There is no sovereign national centre equivalent to that of the United States, Japan or Canada (let alone Russia, set to become the 8th member), even though the complexity of the current EU institutional framework leaves substantial room for manoeuvre to the United Kingdom and to the three large members of the eurosystem.

The question of external representation of the EU has been a source of controversy at least since its creation. Due to the fact that the EC has participated in the discussions of the G-7 since 1977, the four EU (three eurozone) members tend to ignore their eleven (eight) "peers" when global affairs are on the agenda. The same applies to the OECD, where the EC also participates. At the IMF, like in the 
G-7, a representative of the ECB addresses all matters directly pertaining to monetary policy.

The ambiguity of the solutions reflects, once again, the complexity of the EU institutional framework. Nevertheless, the strengths of the perspective can be put to good use in the global arena, as long as the procedures underlying the eurosystem are understood along the lines of the schemes of "flexible integration" discussed next.

\subsection{Principles of variable geometry}

The EU MSF does not focus on balance of payments adjustment, but rather attempt to bring together principles of good government commonly accepted and which indeed are jointly transferred to Community institutions. The degrees of commitment to the EU and to each one of its main institutions have been changing in various issue areas, as a partial response to a more turbulent global and regional environment. The creation of the eurosystem in January 1999 was followed by a difficult institutional period, which has also delayed the accession calendar. The delay reflects the propensity to procrastinate on structural reforms, rather than the recurrent European debate about whether multiple-speed convergence towards union objectives is possible and desirable.

This debate does help to illustrate the complementarity between global and regional common good. One extreme position in the European debate draws on the view of a unified constitutional state, for which variable geometry is impossible. The other extreme position calls for a set of contractual arrangements, where common institutions are undesirable.

From the beginning, the European Community attempted to transcend the rigid intergovernmental nature of the OECD or of the G-7 (which does not even have a permanent secretariat) in the direction of supranational institutions like the EC. But the convergence stopped far short of establishing Community-wide democratic legitimacy. As a consequence, the institutional framework became more and more complex, especially after a Union with three pillars, the Community and two intergovernmental ones that were created in the 1992 Maastricht Treaty. In the process, flexibility was lost and this is why the debate about multiple-speed convergence towards union objectives has resurfaced. Another reason is, of course, the imminent enlargement.

For any given number of member states, there is a trade-off between the freedom to enter into contractual agreements, which include some members and exclude others and the ultimate requirement of "one man, one vote", which would be associated with a new state emerging from the integration of all members. In Fig- 
ure 1, adapted from CEPR (1996, p. 47), the vertical axis measures flexibility and the horizontal axis measures depth of integration. The origin represents purely intergovernmental co-operation among the same member states. The vertical axis represents economic efficiency and executive performance, or the forces of competition, while the horizontal axis represents legal status and legislative activity, or the forces of co-operation. Each point in the quadrant can therefore be seen as a combination between competition and co-operation.

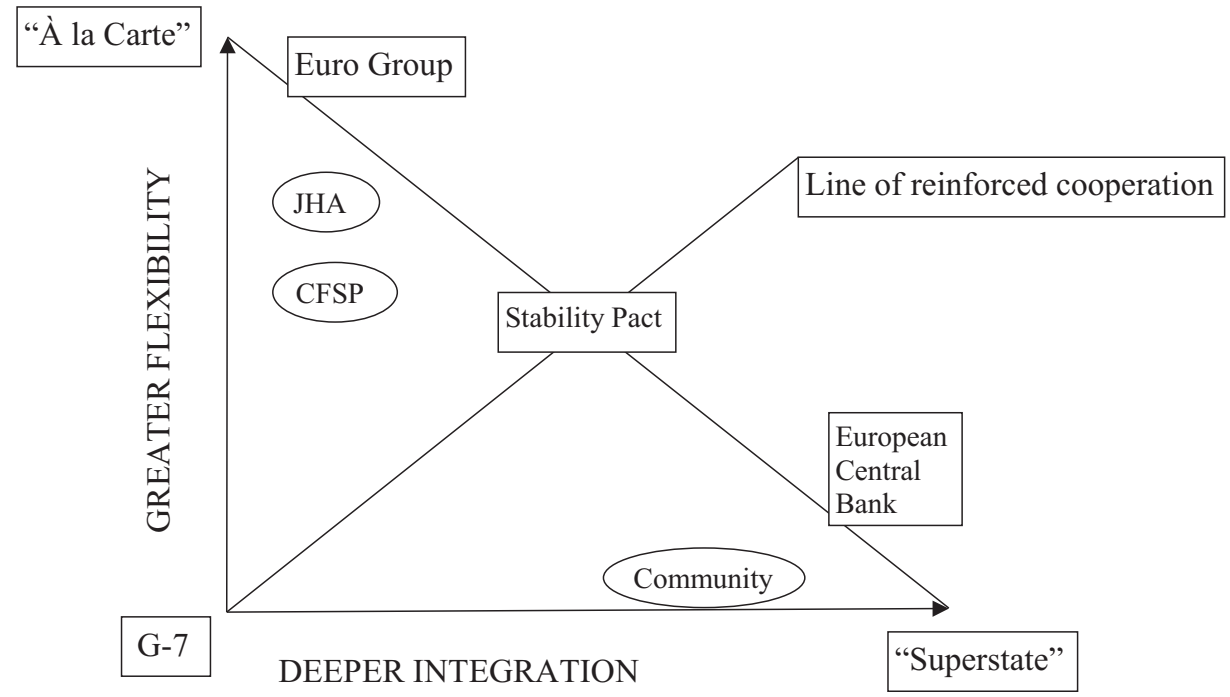

Figure 1

The highest point on the vertical axis, labelled "à la carte", would be equivalent to a purely contractual institutional design where any combination of subgroups of member states is acceptable, so that the basic intergovernmental principle of equality of member states applies and unanimity in decision making is preserved. During the revisions of the Union treaty in 1996 and 2000, intergovernmental schemes of "reinforced co-operation" have been called for among some member states, as their creation still requires unanimity of all member states and their membership is open to all of the member states who qualify (Macedo [1995] describes the positions taken by the Portuguese parliament in favour of "positive variable geometry").

These manifestations of flexible integration are consistent with the operation of the principle of proximity (or subsidiarity) mentioned at the outset, according to which further decentralisation is acceptable and desirable. Indeed, CEPR (1996, 
p. 65) mentions a generalised subsidiarity principle, where decentralisation can go towards groups of states, rather than local and regional bodies within each state.

The horizontal axis would go to the extreme where majority voting applies to the voting population without regard to its national location, labelled "superstate". The co-operation among the (former) member states would cease to be relevant politically, economically or socially. Quite clearly, even in areas where single policies have existed for a long time, such as tariffs, and the EC has an undisputed mandate, the relevance of the member states is always there. The same can be said about monetary policy, administered by the eurosystem.

With respect to the objective of a free movement of persons, it was achieved properly for the first time on 19 March 1995, by the seven member states (Belgium, France, Germany, Luxembourg, the Netherlands, Portugal and Spain) that are parties to the Schengen convention. When the Treaty of Amsterdam came into force on 1 May 1999, the freedom of movement was extended to all others, with the exception of the United Kingdom and Ireland.

Not all combinations of flexibility and integration defined by the two axes are possible, let alone desirable. In effect, for each specific issue-area, when integration becomes deeper, purely contractual arrangements are constrained and when the principle of equality between members is sacrificed to the democratic deficit, flexibility is constrained. Therefore a downward sloping line can be defined between the point of maximum flexibility and no common institutions and the point to the right that deeper integration would prevent any flexibility in the co-operation among member states. The intersection should be to the left of the point labelled "superstate".

It is assumed that along the 45 degree line, there is a balance between integration and flexibility. This means that flexible integration schemes along this line will balance the contractual commitment and the deeper integration, as called for by schemes of "reinforced co-operation" mentioned above. If the combinations of a common base and open partnerships defined in functional rather than geographical terms (CEPR, 1996, p. 59) were along this line, they would balance integration and flexibility in the best possible way, given the number of states involved.

The creation of the EU called for new institutions such as the ESCB while the excessive deficit procedure regulated the surveillance in the area of budgetary policy required for a sustained operation of the eurosystem. Increased intergovernmental co-operation, common foreign and security policy (CFSP) and justice home affairs (JHA), the latter in conjunction with the free movement of people and the creation of a common asylum and immigration policy. These institutional procedures have been put in place gradually but this has not overcome the fact that the architecture resulted from last-minute negotiations at the European Council in Maastricht rather than from an explicit commitment to flexible integration. 
As shown in Figure 1, the array of open partnerships provided by the two pillars complements the Community as a very significant base including all members, but the areas of interaction are limited. In the economic and financial area, on the contrary, the ECB and the Euro Group are complemented by the SGP. In all three set-ups, but especially in the SGP, countries not in the eurosystem follow the rules anyway. Moreover, Denmark continues to follow the ERM code of conduct.

In any event, the resulting institutional framework is extremely complex with areas of duplication and inefficiency alongside areas where resources are insufficient. This applies to the various secretariats, but also to the EC itself, which has been involved over some years in a difficult internal restructuring. Whatever is the place of the entire Community architecture in Figure 1, the combination of the three pillars is unlikely to be along the diagonal. Probably a legalistic approach would place the union architecture more towards the Community than towards the intergovernmental pillars. While the common base remains difficult to distinguish from open partnerships nearly ten years after the Union treaty was negotiated, with the revisions agreed at the European Councils in Amsterdam and Nice, there is a suspicion that the balance has tilted towards the vertical axis, but so far without noticeable improvements in executive performance.

Since all member states have met the entry criteria for monetary union (independently of the willingness to join for Denmark, Sweden and the United Kingdom), the case for flexible integration has been strengthened by the euro. There is also greater acceptance that variable geometry was inevitable in the case of a single currency. Jacquet and Pisani-Ferry (2000) note in closing that the Nice Treaty provides the possibility of making use of "reinforced co-operation" in the field of economic and monetary union.

In sum, the flexibility approach to European integration stresses the portability of the European experience to countries in different stages of economic and financial development. As such it may facilitate enlargement. But it also helps to improve the EU institutional framework, especially its financial architecture, now that the stability culture prevails among its 15 members.

Political integration objectives imply that the process of European monetary integration required a fundamentally different MSF from the one that would be called for among transition and emerging markets, as long as they start earning credibility abroad while retaining national cohesion.

\section{THE DANGER OF PROCRASTINATION}

The prospects for the portability of EU procedures must recognise one negative aspect of the eurosystem. National governments have used the euro as an excuse 
for procrastinating on unpopular but essential structural reforms. Yet, even if the euro-based MSF is effective, it cannot replace reform in labour markets, social security, education and training etc. Only if reforms take place will medium-term credibility be ensured so that replacing national currencies with the euro will have effects according to the credit ratings of nations, cities and firms rather than their geographical location.

Indeed if countries use EMU to procrastinate on their unpopular reforms, the benefits of the stability culture may vanish both at the core and at the peripheries. The "hold up" problem in the industrial organisation literature, mentioned in this connection by Buiter and Sibert (1997), suggests the similar danger of a "euro hold up" (Macedo, 1998).

Traditionally, system stability has been provided by the largest national economy. The provision of the international public good is made in ways that are often determined by national traditions and institutions. The provision of the international public good is also in the national interest, which in this case is often represented by institutions sensitive to the needs of the taxpayer and therefore more prone to understand and fight against the incentive of each one of the member countries to free ride. As there is no dominant player in the EU, procedures relying on an agreed MSF had to be devised and implemented.

The incentive to free ride on the public good is indeed greater for the small countries, but without a decision to join, which can be domestically supported, the benefits of convertibility and stability are also less apparent.

The public good element of the euro cannot be achieved against market sentiment, but policy credibility can overcome hierarchy. Any solution not based on the national cohesion of the member states would be unstable. No member-state is likely to remain in a slower speed of convergence against its national interest, expressed by majority vote. National and union cohesion thus became requirements for the competitiveness of European business worldwide.

In other words, the euro is largely an enabling reform that requires additional structural adjustment. If carried out by the EU states, structural reforms would not only enhance the potential of the euro as a world currency, but also the competitiveness of European firms.

In spite of the MSF, myths from a misperceived historical experience may interact perversely with geography. The fact that the reputation of a state in the peripheries of international currency standards may differ from that of a state in the core basically reflects the role of politics. In effect, the interaction between the commercial interests of the middle classes and the diplomatic aspirations of the central banks was already political during the gold standard. With the euro, this interaction remains political and determines whether reforms are enduring, so that employment-generating growth can be stronger. 
Because of the propensity to procrastinate described above, the role of the EU cannot be divorced from that of the institutions of global economic and financial governance who have, in one way or another, helped to prevent the 1997-99 financial crisis in emerging markets from becoming a 1930s style global depression. This is true in spite of the spectacular interruption of the Millennium Round of the WTO launched in Seattle in late 1999 and of subsequent protests at meetings of the Bretton-Woods institutions. While it is essential to empower people to face the challenges of globalisation, the changes in governance that are called for cannot become protectionist without threatening the basic benefits of open trade in goods, services and assets, let alone the free movement of people.

\section{LESSONS FOR EMERGING MARKETS}

\subsection{The legacy of financial crises}

After the 1992-93 crises, then, successive emerging markets were similarly hit, especially during 1997-99. The fact that few opportunities for testing the credibility of exchange rate parities were missed by market operators made the exchange rate regime as crucial a determinant of macroeconomic stability as fiscal, debt management and banking policy. Calvo (2000) shows that pure floating is beyond most emerging markets. This perception rationalised direct policy responses such as exchange controls, perhaps along the lines of the so-called Tobin tax on short-term capital movements. Bartolini and Drazen (1997) stress the credibility effect of capital account liberalisation. See also Dornbusch (1998). A more cautious stance can be found in Eichengreen (1999).

Financial crises have caused hardship in individual countries, but to date they have not threatened globalisation. Any tendency to draw back from world financial markets, as in Malaysia, has been isolated and temporary. The debate about Malaysia's crisis is summarised in Edwards and Frankel (2001), with Dornbusch (2001) taking the position that the general presumption against controls remains.

The same presumption applies to the Chilean experiment, described in Reisen (1999). So as to revive the domestic stock market, Chile lowered its barriers in spring 1998 to short-term capital inflows (a tax called encaje) and set the tax rate to zero in autumn for a few months. Even a country endowed with a relatively well functioning administration found it difficult to keep an exchange control geared to a long-term objective when the environment became turbulent. The objective was to improve the composition of capital inflows towards long-term instruments, especially foreign direct investment relative to short-term flows, which were considered more volatile. In any event, the rationale for the encaje was clear during 
the boom of the mid-1990s, but ceased to apply afterwards, reinforcing the idea that such measures work temporarily and only if they are introduced in good times.

The problem is rather how to tailor macroeconomic and financial arrangements to the imperatives of globalisation and in particular to limit the vulnerability of the domestic economy to the crisis problem. The complexity of this problem is evident in the exchange rate dilemma. It has become clear that exchange rate systems involving fixed, but adjustable rates, bands and crawls are increasingly crisis-prone. One alternative is to float more freely, as such Latin American countries as Brazil, Chile, Colombia and Mexico and such Asian countries as the Philippines, Korea and Thailand have begun to do. Another alternative is to adopt a hard currency peg, as in Argentina and Hong Kong. This has stimulated discussion of dollarisation as a mechanism for installing hard pegs in Mexico and various Central American countries, notably Ecuador. In any case, dollarisation cannot resolve this exchange rate dilemma (Edwards, forthcoming).

If there is a difference between the management of the EMS crises and that of emerging markets, it is the importance of international banking supervision, which was more explicitly acknowledged in the late than in the early 1990s. It includes better risk management along the lines proposed by the Bank of International Settlements (BIS) and would also support the creation of new networks including major emerging markets, such as the Basle Committee of the BIS or the G-20 (Braz and Macedo, 2000).

It may be, then, that the crisis encouraged responses that would not have been possible in calmer periods, in this sense serving as a coordinating device. Bank restructuring, which took place during the crisis may not have otherwise happened; as a result, debt structures are in better shape now than if countries had postponed reforms.

Once again, the lesson of widening the ERM bands was that the MSF must go beyond exchange rate surveillance. Moreover, it is by allowing responses that would not obtain in calm periods that financial crises serve as co-ordinating devices. In effect, co-ordinated systems like the one implied by the ERM code of conduct are difficult to adapt to a world system without shared values, even when they refer to what is essentially a shared variable, the exchange rate.

The exchange rate regime is just one instance of needed improvements in financial architecture. Nevertheless, it plays a central role in the debate on the reform of the system of international relations and its main institutions, which for the most part were established in the aftermath of World War II. The portability of the European MSF on a broader scale presumes that the exchange rate regime is well defined. 
Since the best indicator of policy credibility is that a MSF exists and is effective, a way out of the "don't fix, don't float" conundrum is that - as stressed in section 2.4 above - you may have to float in order to fix. As a consequence, the MSF that is emerging outside the EU does not imply a single exchange rate regime among them.

\subsection{Multilateral surveillance framework: global vs. regional?}

The interpretation of the European experience presented above is consistent with the view that the creation of the euro does not reflect a collective hard peg, but it goes beyond that. In effect, the case made for flexible integration turns the European MSF into a more easily portable institution than the usual interpretation along political integration lines. As suggested above, even the interpretation of European integration as determined by the Franco-German post-war alliance is inadequate, for the effects of peer pressure applied in similar measure to Italy and to the Benelux countries. Of course, an Argentine-Brazilian integration momentum would have positive effects for Mercosur, but the role of the smaller states could still not be neglected. Chile, an associate member, may be as crucial to Mercosur as the United Kingdom was to the promotion of the ERM code of conduct - and hence to the success of the euro!

While a MSF does not imply a common exchange rate regime, its credibility does presume that devaluations and exchange controls can be co-ordinated at the regional or global level, to lessen their beggar-thy-neighbour. This presumption, in turn, is predicated on handling the pattern of contagion. Geography and hegemony seem to play a role, with some evidence pointing to the role of trade and to listings of country potentials that owe more to marketing than to fundamentals. Hegemony is used in the sense of "winner takes it all". For example, in the competition among potential locations for international investment (akin to the "beauty contest" in financial circles), the result may be that some markets are crowded and others deserted. Glick and Rose (1998) have a trade explanation, which might account for the "geographic fundamentals" described in section 2.3 above. The "winner takes it all" is like the "superstar model" of the labour market popularised by Krugman (1994, p. 149).

Both geography and hegemony are at work when it comes to the economic policy autonomy of Hong Kong, relative to China during the attacks on the currency board. The fragility of the Asian recovery also involves both geography and hegemony, as long as Japan does not recover. The turmoil in Russia in the summer of 1998 had a strong domestic component, which threatened to reverse the transition process. In spite of improvements in the credibility of policy (and of Russia's par- 
ticipation as equal in the G-7 discussions), the debt moratorium and currency inconvertibility dented the process of earning external credibility.

Given the importance of contagion, useful inputs into crisis management come from investigating its regional patterns. Emphasis was given to the European exposure to multilateral surveillance mechanisms. This is not to say that peer pressure mechanisms are absent from international financial institutions. It simply reflects the widely acknowledged fact that there are often four or more European voices in the face of the United States and Japan. That being said, geography is sometimes cast in a trilateral fashion, which rather suggests architecture based on three powerful blocs.

The informal apportionment of responses to financial crises in emerging markets to the major mature democracy in the same continent suggests a pattern of contagion reminiscent of "the Monroe doctrine" and is probably inadequate in today's global markets. There have been proposals to revive regional arrangements along the same lines, so as to facilitate a new financial architecture. Effects in Brazil or in other parts of Latin America are already seen as primarily calling for a US response. Instead, given Russia's status as former super-power in Europe and parts of Asia, perceptions of crisis there elicit stronger responses by the US and by the EU. Central Europe is seen as a European problem, especially in what pertains to the ten applicants for membership (seven CEFTA members and the three Baltic states).

\section{CONCLUSION}

When improved governance does not accompany globalisation, people are likely to feel excluded from its benefits. Accordingly, the new financial architecture should provide global markets with supervision allowing for regional and national diversity. Indeed, events in the last few years (such as the rapidity of American response to Russia's 1998 financial crisis, Japan's difficulties and an apparent European indifference to emerging markets) have made perceptions in major economies more diverse than they had been in decades. Moreover, the fluctuations of the dollar and the yen against each other during the last two years suggest the doubts of markets that combination of unity with national diversity could be achieved anytime soon.

Yet co-ordination mechanisms among monetary and fiscal authorities like the ones found in the EU have been the best response to threats of contagion of national crises. In effect, the current international system goes beyond American national interest in preserving world stability and it calls for more effective regional and global responses adapting EU methods. 
Without a credible MSF like the one found in the EU, neither currency devaluations nor exchange controls can be co-ordinated at the regional or global level, so as to lessen their beggar-thy-neighbour character. The MSF, which evolved from the ERM code of conduct, may apply to members of the Chang Mai initiative or of Mercosur by means of peer pressure. There has been no formal application to relations within CEFTA in part because the candidate countries are already greatly involved with the EU.

Over and above the parallels between the 1997-99 emerging markets crisis and the Mexican devaluation of December 1994, the lessons from the crises in the ERM may indeed be helpful in designing a new international financial architecture. In effect, the crises were overcome by the ERM code of conduct.

With the experience gathered during the first two years of the euro, a new code of conduct may be developing, which acknowledges the importance of international banking supervision, including better risk management along the lines proposed by the BIS. Avoiding contagion by reverting into trade and financial protectionism could well prove as ultimately futile a beggar-thy-neighbour policy now as it was in the early 1930s.

The potential costs, stability and magnitude of private capital flows to developing countries are an important criterion to assess current proposals to reform the functioning of the international financial system. In this regard, there have been proposals for regional fora, which could help the IMF improve its performance when exchange rate and banking issues are difficult to disentangle, as is more and more frequently the case. While this is certainly true, institutions of global governance have been essential in preventing the 1997-99 financial crises in emerging markets from becoming a 1930s style global depression. They will be greatly needed in the future as well.

The usefulness of the euro for international financial architecture hinges on recognising the role of the OECD and the BIS, where peer pressure and yardstick competition have been applied for decades, and the proposals for flexible European integration. It will be also critical to ensure that regional economic and financial institutions are complementary to the global ones (IMF, World Bank and WTO).

The immediate effect of the 1997-99 emerging market crises is to underscore a lesson from the inter-war period: liberalisation and globalisation must be managed in order to face the threat of protectionist pressures, which could conceivably spread from the tariff escalation to non-tariff barriers like exchange controls. Therefore, containing financial instability means avoiding a relapse of protectionism while fostering reform in the international system. This will allow for a more effective regional and global response to threats of contagion of national crises. In short, it is widely acknowledged that globalisation calls for better governance at 
national and global levels. Our interpretation of the European experience suggests that regional governance based on peer pressure may be a crucial ingredient for better governance at national and, indeed, global levels.

\section{REFERENCES}

Bartolini, L. and Drazen, A. (1997): Capital Liberalisation as a Signal. American Economic Review, March.

Bergsten, F. (2000): The New Asian Challenge. Institute for International Economics. Working Paper.

Besley, T. and Case, A. (1995): Incumbent Behavior: Vote Seeking, Tax Setting and Yardstick Competition. American Economic Review, March.

Bliss, C. and Macedo, J. B. (eds.) (1990): Unity with Diversity in the European Community. Cambridge: Cambridge University Press.

Bordo, M. and Rockoff, H. (1995): The Gold Standard as a Good Housekeeping Seal of Approval. NBER Working Paper no. 5340.

Braz, J. and Macedo, J. B. (2000): Risk Management and Financial Globalisation. OECD Development Centre.

Buiter, W. and Sibert, A. (1997): Transition Issues for the European Monetary Union. Mimeo.

Buti, M., Franco, D. and Ongena, H (1997): Budgetary Policies during Recessions: Retrospective Application of the 'Stability and Growth Pact' to the Post-War Period. European Commission, DGII, Mimeo, Brussels.

Calvo, G. (2000): The Case for Hard Pegs in the Brave New World of Global Finance. OECD Development Centre.

CEPR (1996): Flexible Integration, Towards a more Effective and Democratic Europe, Monitoring European Integration 6, London.

Cooper, R. (1968): The Economics of Interdependence. New York: Mc Graw Hill.

Decressin, J. and Dysiatat, P. (2000): Capital Markets and External Current Account: What to Expect from the Euro. IMF Working Paper, WP/00/154.

Dornbusch, R. (1998): Capital Controls: An Idea whose Time has Gone. MIT.

Dornbusch, R. (2001): Malaysia's Crisis: What was Different? In: Edwards, S. and Frankel, J. (eds): Preventing Currency Crises in Emerging Markets. Chicago: University of Chicago Press, forthcoming.

Edwards, S. (2001): The False Promises of Dollarisation. Financial Times, 11 May.

Eichengreen, B. (1999): Towards a New International Financial Architecture a Practical Post Asia Agenda. Washington IIE.

European Commission (1990): One Market One Money: An Evaluation of the Benefits and Costs of Forming an Economic and Monetary Union. European Economy, No. 44, October.

Frankel, J. and Rose, A. (1996): The Endogeneity of Optimum Currency Areas. NBER Working Paper, No. 5700.

Glick, R. and Rose, A. (1998): Contagion and Trade: Why are Currency Crises Regional. CEPR Discussion Paper, No 1947.

Gros, D. et al. (2000): Quo Vadis Euro? The Cost of Muddling through. Brussels: CEPS.

Jacquet, P. and Pisani-Ferry, J. (2000): Economic Policy Coordination in the Euro-Zone; What has been Achieved? What should be Done? London: Center for European Reform.

Krugman, P. (1994): Peddling Prosperity. New York: Norton. 
Macedo, J. B. (1995): Multiple Allegiances as Fate. Available at www.fe.unl.pt/ jbmacedo Macedo, J. B. (1996): Portugal and European Monetary Union: Selling Stability at Home, Earning Credibility Abroad. In: Torres, F. (ed.): Monetary Reform in Europe. Lisbon: Catholic University Press.

Macedo, J. B. (1998): Portugal. In: Fukasaku, K. and Haussmann, R. (eds): Democracy, Decentralisation and Deficits in Latin America. OECD Development Centre, pp. 191-200.

Macedo, J. B. (2000a): Converging European Transitions. The World Economy, November.

Macedo, J. B. (2000b): Financial Crises and International Architecture: A "Eurocentric" Perception. OECD Development Centre Technical Paper. No. 162.

Macedo, J. B. (2001): Statement to the Preparatory Committee of the UN Financing for Development Conference. New York, 20 February.

Available at www.fe.unl.pt/ jbmacedo/oecd.un.htm

Macedo, J. B., Nunes, L. C. and Covas, F. (1999): Moving the Escudo into the Euro. CEPR Discussion Paper. No. 2248.

Macedo, J. B., Eichengreen, B. and Reis, J. (eds) (1996): Currency Convertibility: the Gold Standard and Beyond. London: Routledge.

Reisen, H. (1999): After the Great Asian Slump: Towards a Coherent Approach to Global Capital Flows. OECD Development Centre Policy Brief. No. 16.

Shleifer, A. (1985): A theory of Yardstick Competition. Rand Journal of Economics, Vol. 16, No. 3, Autumn, pp. 319-327. 